\title{
Los regímenes autoritarios centroamericanos de los años treinta. Balance historiográfico y perspectivas de investigación
}

\section{Central American Authoritarian Regimes during the 1930s: A Historiographic Assessment and Research Perspectives}

\author{
Luis Gerardo Monterrosa Cubías \\ (D) https://orcid.org/0000-0002-5846-7418 \\ UNAM, Centro de Investigaciones Multidisciplinarias sobre Chiapas y la Frontera Sur, \\ Becario del Programa de Becas Posdoctorales de la UNAM, México, Chiapas
}

gerardomonterrosa20@gmail.com

Resumen:

En este artículo se realiza un balance historiográfico de los regímenes autoritarios instaurados en Centroamérica durante los años treinta del siglo xx. Para concretarlo fueron seleccionadas y analizadas cuatro obras. Primero, explicando tres temáticas que aparecen en sus páginas, tales como la toma del poder y el talante providencial de los gobernantes, las formas de preservar el poder y sus relaciones con Washington. Segundo, estableciendo diferencias metodológicas entre estos abordajes e indicando rutas de investigación incentivadas por estos trabajos.

Palabras clave: régimen político, autoritarismo, poder, historiografía, archivos.

\section{Abstract:}

This article carries out a historiographic assessment of the authoritarian regimes installed in Central America during the 1930s. Four sources were selected and analyzed for this assessment. The article first explains three themes that emerge from these sources: the seizure of power and the rulers' providential mental framework, their way of preserving power, and their relationship to Washington D.C. The article then proceeds to identity the methodological differences between these four sources, pointing to the research pathways that these works foster.

Keywords: political regime, authoritarianism, power, historiography, archives 
Peso del aire, vuelo de la tierra, En opuesta verdad y simbolismo.

Doble color del cielo y del abismo Que el ojo exacto de la vida encierra.

Sal aceptada. Dulcemente en guerra. paisaje del espejo y de ti mismo. Isla del sueño. Musical bautismo. Ángel sin voz que amarra o que destierra.

Vamos - niños de polvo, gotas ciegas-, en ansias verticales o vencidas cumpliendo lo mandado por entregas.

Es anillo de muerte el que nos junta: Y en asombro de encuentros y partidas Se vuelve de ceniza la pregunta...

CLAUdia LARS, Hermanos

\section{Introducción}

\section{E} secretario de Relaciones Exteriores durante el gobierno de Ávila Camacho, Ezequiel Padilla, remitió un comunicado a su homólogo de Gobernación en diciembre de 1943. En estas líneas mostró su enojo por el activismo político de algunos exiliados centroamericanos, radicados en México, que generó el reclamo de los gobiernos amigos. "Como es sin duda del conocimiento de esa Secretaría —escribió Padilla - a principios del año en curso se constituyó en México una agrupación denominada Unión Democrática Centroamericana, [...] integrada por emigrados». ${ }^{1}$ Sus miembros: militares, académicos y figuras políticas habían sacado provecho de sus contactos, de los recursos económicos y la hospitalidad del gobierno mexicano para publicar artículos y celebrar más de una reunión en el Palacio de Bellas Artes. Atacaron a los regímenes de sus respectivos países, causantes de su destierro, y emplearon las secciones de su revista Centro América Libre para exigir cambios políticos.

\footnotetext{
1 Comunicación del secretario de Relaciones Exteriores de México dirigida al secretario de Gobernación. México D. F., 16 de diciembre de 1943, Archivo Histórico Genaro Estrada, Secretaría de Relaciones Exteriores de México, expediente III-661-1.
} 
Claudia Lars, Luis Cardoza y Aragón y Heliodoro Valle, personajes insignes de las letras del istmo, compartían afanes con oficiales como José Asensio Menéndez. No dudaron en hacer oír su voz, pero comprometieron también al gobierno que les daba cobijo. Vicente Sáenz, escritor costarricense y secretario general de la agrupación aludida, expresó ante la segunda reelección del presidente salvadoreño Maximiliano Hernández Martínez (1931-1944): «¿Reconocerán este nuevo atentado contra la democracia las cancillerías del nuevo mundo? ¿Le seguirán dando su mano a Martínez - y a los otros tiranuelos centroamericanos - los gobiernos a fe cierta antitotalitarios de este continente, con Mr. Franklin Roosevelt y Mr. Henry Wallace a la cabeza o en el tope?» (Sáenz, 1944:177).

A mediados de los años cuarenta, cuando los aliados lograban triunfos decisivos en la segunda guerra mundial, la sociedad centroamericana sufría los efectos del continuismo y la represión de los regímenes instaurados en los años treinta. De hecho, los intentos por silenciar las críticas opositoras que llegaban desde el extranjero formaban parte de estos síntomas.

Como bien ha indicado Arturo Taracena, los efectos de la crisis económica suscitada en 1929 hicieron patente la debilidad del Estado liberal oligárquico, el cual alcanzó características precisas desde que la exportación cafetalera definió los objetivos de la elite en el poder. A partir del último cuarto del siglo XIX, el aparato estatal fue afinado para que los finqueros tuvieran la mano de obra requerida. Se otorgaron concesiones a las empresas extranjeras con el propósito de construir vías de comunicación y se mantuvo al grueso de la población totalmente excluida de las decisiones políticas. "Orden y progreso» era también el lema del segundo periodo del liberalismo en Centroamérica. Sus máximos exponentes —como Justo Rufino Barrios en Guatemala- eran jueces y partes del proyecto político adoptado. ${ }^{2}$ Ciertamente, las variaciones en los precios del café en el mercado internacional acecharon siempre la estabilidad del sistema monoexportador; sin embargo, cuando la crisis tocó la puerta de las naciones compradoras y el precio del producto tendió a la baja, "el proceso de legitimación — por demás precario- saltó por los aires, dando paso en cuatro de los cinco países históricamente centroamericanos a la dictadura militar personalizada» (Taracena, 1993:178).

Jorge Ubico en Guatemala, Maximiliano Hernández Martínez en El Salvador, Tiburcio Carías Andino en Honduras y, para completar las patas de la mesa,

2 "Sin duda, durante el gobierno de Barrios la economía de Guatemala cambió radicalmente con más énfasis en la producción y exportación de café y una mayor concentración de la tenencia de la tierra y la riqueza. Sin el menor sonrojo, el general Barrios se jactaba de ser el mayor productor del café de su país" (González, 2014:141). 
Anastasio Somoza García en Nicaragua. Estos fueron los hombres que tomaron el poder cuando la lucha fratricida entre caudillos y la movilización ascendente de las clases trabajadoras - condicionados en buena parte por la crisis económica-colocaron en riesgo el buen funcionamiento del modelo agroexportador. Su forma de administrar el poder: clausurando los espacios políticos, cooptando a los cuadros más beligerantes o derrocando a aquellos que opusieron resistencia, estuvo lejos de encarnar una casualidad. El hombre fuerte o el líder requerido había tomado el poder para acabar con la anarquía y conquistar el anhelado orden. Todos, más allá del contexto en que arribaron, fueron vistos como providenciales, al mejor estilo de los personajes de Augusto Roa Bastos, Ramón del Valle Inclán y Alejo Carpentier, y muy pronto ratificaron dicha condición.

Es aventurado suponer que desde el principio hubieran pensado en perpetuarse en el poder, pero es factible considerar que su forma de ejercerlo y las alianzas entabladas permitían dicho propósito. Mucha tela de dónde cortar acerca de estos regímenes, sus dinámicas y su herencia. Ahora bien, ¿qué se ha escrito al respecto? ¿Qué investigaciones pueden destacarse?

En este artículo pretendo seleccionar y revisar aquellas obras en las que, mediante consultas de fuentes primarias, fueron objeto de estudio los regímenes autoritarios de los años treinta en Centroamérica. De hecho, es necesaria una delimitación, pues no puede examinarse en este breve artículo todo lo discutido sobre el tema, a riesgo de incurrir en una superficialidad dolosa.

Si bien la historiografía centroamericana ha carecido de un desarrollo tan intenso como la mexicana, donde sus investigadores se dedican por completo a su quehacer, también es verdad que los regímenes en cuestión han despertado un interés que no puede circunscribirse al plano académico. Muchos volúmenes disponibles en las bibliotecas llevan la firma de críticos o apologetas de los dictadores. Se trata, por consiguiente, de elementos que analizaron este periodo político para justificar su actuación o sus opiniones personales. No pretendo abordar aquí con minuciosidad estas obras, que bien pueden ser tema de otro artículo; más bien intento colocar ejemplos que fundamenten el talante prolífico apuntado y tender puentes hacia el objetivo trazado.

\section{Entre denuncias y halagos a los regímenes autoritarios}

Pedro Joaquín Chamorro, capturado y torturado luego de que el poeta Rigoberto López asesinara a Anastasio Somoza en 1956, y Efraín de los Ríos, quien conoció 
las cárceles del ubiquismo, donde casi perdió la vida, blandieron su pluma para describir la represión oficial. ${ }^{3}$ Su propósito, lejos de la pretendida objetividad, radicó en plasmar el suplicio vivido y denunciar la condición opresiva que debía borrarse -en el caso de Chamorro- o nunca más repetirse. Efraín de los Ríos ilustró a cabalidad este aspecto:

Si el ilustre manco de Lepanto escribió su Don Quijote con la intención de ridiculizar y hacer que desaparecieran las costumbres de los andantes caballeros — vengadores de agravios y desfacedores de entuertos-, yo, zorro perdido en este rastrojal de América, escribí Ombres contra Hombres, con la intención de que las nuevas generaciones que formarán la posteridad, abominen las tiranías, odien cualquier forma de despotismo y sepan luchar en defensa de sus libertades ( De los Ríos, 1948:iv).

Estirpe sangrienta: los Somoza, como Chamorro tituló su libro, se publicó por primera ocasión en 1957. En sus líneas criticó el poder absoluto que desplegó durante veinte años el fundador de la dinastía. Describió, además, las mazmorras del somocismo y lanzó acusaciones contra el dictador. Esta forma de fabricar un relato acusador fue emulada por otros que, sin haber experimentado estas vejaciones, cifraron su esfuerzo en revisar lo sucedido en El Salvador durante el gobierno del general Martínez (1931-1944).

En trabajos como el de Francisco Morán (1979) y David Luna (1969), aunque este último incluyó un análisis de la estructura económica, abundan las descalificaciones y burlas al general. Aquí sus creencias teosóficas - practicadas por muchos intelectuales en los años veinte (Casaús y García, 2005) — suscitan los comentarios más abyectos, soslayando puntos prioritarios en el abordaje del régimen, como pueden ser, por ejemplo, sus pactos con la oligarquía o aquellos mecanismos adoptados para controlar y cooptar a la población. Se trata, por ende, de cuadros pintados en blanco y negro, en los que impera el segundo color sin ningún tipo de matiz. Interpretaciones construidas desde un señalamiento: en el caso de Morán como el gobierno que pisoteó los anhelos democráticos por más de un decenio y desde la apreciación de Luna como el régimen que inauguró la

\footnotetext{
${ }^{3}$ El asesinato de Somoza en León, Nicaragua, fue abordado desde el ámbito literario por Sergio Ramírez Mercado en su obra Margarita, está linda la mar (Ramírez, 1998). "La trama de la novela es doble y son dos los universos diegéticos: en el presente del relato, año 1956, se narra la conspiración para matar a Somoza García y su ejecución realizada por Rigoberto López Pérez, poeta y periodista. En ese presente se lee la historia escrita por ese mismo personaje sobre los dos viajes de Rubén Darío a Nicaragua, uno en 1907 y el otro, ya enfermo, en 1916, como también los sucesos que rodean la muerte del poeta". Moro (2014). Véase también Urbina (2004).
} 
dictadura militar en El Salvador. De hecho, este último autor citó este aspecto en la introducción de su extenso artículo al afirmar: «Todas las cosas que suceden en nuestros días tienen ahí un lógico antecedente; la sombra de este régimen sigue nuestros pasos con más o menos intensidad, en casi toda nuestra vida política, social y cultural» (Luna, 1969:42).

Ahora bien, si la sombra de esta dictadura fundante ocupaba todo resquicio y, por lo tanto, era preciso estudiarla para diseñar la estrategia idónea en el combate del militarismo, otros trabajos, plagados de adulación hacia el gobernante y una visión triunfalista de su régimen, recorrieron el sendero contrario. Martínez y Ubico, por colocar algunos ejemplos, fueron elevados a los altares patrios como dirigentes que enrumbaron la política nacional hacia el progreso (véase foto 1).

Fuente: El Día, 5 de febrero de 1932, El Salvador, p. 1

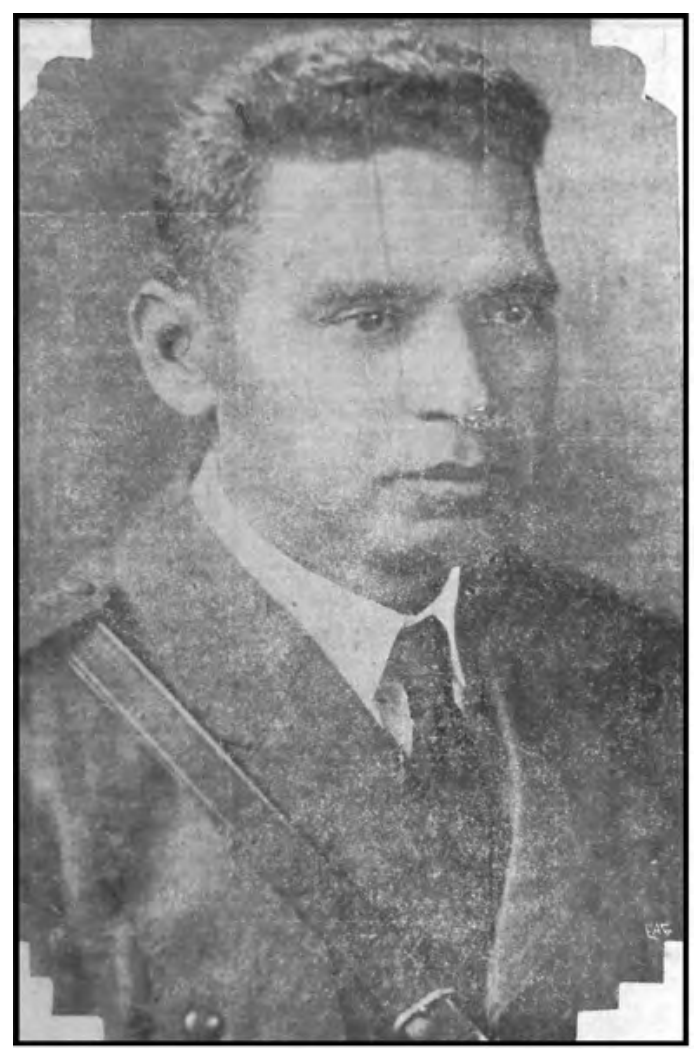

Foto 1. Maximiliano Hernández Martínez

Los textos adscritos a esta corriente, ciertamente, han aparecido en contextos distintos y espaciados: desde la biografía de Ubico elaborada por Rafael 
Cardona, el mismo año en que este asumió el poder, hasta hace un lustro cuando Carlos Sabino reivindicó la figura del general y su gobierno. El primero empleó su prosa florida para exaltar al militar que ganó las elecciones sin competidor alguno. Sabino, entretanto, destacó las carreteras construidas, los edificios públicos que aún engalanan la capital guatemalteca —como el de correos- y las visitas de Ubico a los parajes más recónditos del país (véase foto 2).

Fuente: Prensa Libre, 16 de octubre de 2016, Guatemala.

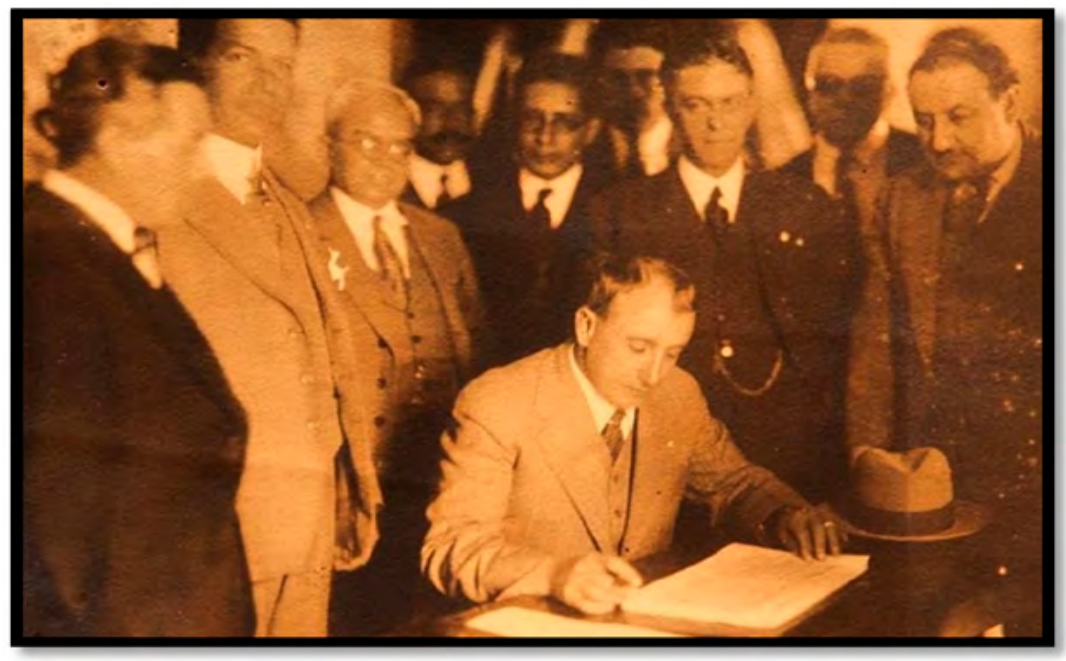

Foto 2. Jorge Ubico (1931-1944).

En pocas palabras, sus párrafos están precedidos por un objetivo: subrayar los avances económicos y de infraestructura forjados durante este periodo sin revisar las componendas y la represión. ${ }^{4}$ Según estos autores, Ubico emergió de un lapso caótico de la historia guatemalteca para instalar el orden e impulsar el progreso. Cardona expresó lo siguiente, como muestra de este ímpetu:

El general Ubico vive desde hace años rodeado de mapas de la república de todo carácter: políticos, orográficos y camineros. De un extremo al otro del país se advierten múltiples líneas del lápiz rojo y azul, por donde va su ideología marcando lo conve-

\footnotetext{
${ }^{4}$ Al abordar los últimos años de Jorge Ubico en el poder, Sabino toca el tema del continuismo y, como sucede a lo largo de su trabajo, justifica dicha acción: "Pero la dictadura de Ubico garantizaba al ciudadano corriente un entorno de absoluta paz y orden, de tranquilidad y de seguridad, con suficiente margen de libertad para desarrollar sus actividades cotidianas y procurar su progreso económico" (Sabino, 2013:214).
} 
niente y descubriendo las zonas apropiadas a las diversas explotaciones del trabajo (Cardona, 1931:26).

Del desgobierno y la anarquía, alentados por un régimen ineficaz y rebeliones comunistas, surgió también el general Martínez, de quien Peña Kampy, locutor de la radio YSS durante el martinato, expresó: el militar gobernó con carácter, firmeza y honestidad. «Por lo tanto —-manifestó- en honor a la verdad, asumió poderes dictatoriales. Pero se puede decir, una dictadura más o menos al estilo patriarcal» (Peña, 1972:69).

En las obras referidas, que integran denuncias y halagos, impera un talante maniqueo que refleja lo controvertido de sus regímenes. Sus nombres permanecen en el imaginario colectivo mediante el bautizo de estadios nacionales en Honduras o la evocación de tiempos idílicos sin delincuencia en Guatemala y El Salvador. Se trata, por consiguiente, de los gobiernos más recordados de la centuria pasada en Centroamérica, particularidad que aún falta por indagar en el terreno de las ciencias sociales. A pesar de esta deuda es pertinente preguntar: ¿qué existe más allá de estas obras fraguadas al calor de la militancia política?

\section{El viraje hacia el trabajo historiográfico}

La respuesta radica en investigaciones que, lejos de vilipendiar ferozmente o tejer encomios, han explicado este tramo de la historia centroamericana. Académicos como Erik Ching, Kenneth Grieb, Roberto Turcios, Mario Argueta y Knut Walter, entre otros, tomaron como fuentes los textos citados y aclararon la posición ideológica desde la cual reflexionaron. ¿Nos hallamos, pues, ante trabajos de mayor calidad? ¿Acudimos a estudios que tornan inadecuada su lectura? Considero que el primer parámetro - mejor o peor obra - es inapropiado en este caso, al igual que todo consejo que proscriba su consulta. Simplemente adoptaron un método de análisis mucho más esforzado —como puede verse en su aparato crítico-, centrado en la formulación de problemas y preguntas, siempre con un sustento documental.

Asistimos, por lo tanto, a interpretaciones de lo sucedido en Centroamérica durante la primera mitad del siglo pasado. Una región caracterizada por el autoritarismo, el protagonismo de los militares, la entronización de caudillos, la injerencia estadounidense y sus empresas en la política interna. Pues bien, ¿cuáles 
serán los trabajos a analizar en los siguientes párrafos? ¿Qué fuentes primarias se utilizaron y qué aportes historiográficos heredaron?

\section{Las coordenadas subjetivas}

El concepto de balance en dos de sus acepciones da sustento al objetivo del apartado. La primera alude al estudio comparativo de una situación o de los factores que intervienen en un proceso para tratar de prever su evolución. En la segunda, concerniente al ámbito económico, se define como el análisis del activo y el pasivo para determinar el estado de cualquier empresa o entidad (RAE, 1992:253). De estas acepciones me interesa destacar cuatro aspectos que brindan elementos para el análisis prometido. En efecto, concretar un balance conlleva una comparación, establecer los factores que intervienen en un proceso, determinar el estado de la empresa y, por último, prever su evolución. Se trata, como puede verse, de cuatro procesos que si se aplican al ámbito historiográfico propician un estudio comparativo de las investigaciones, la revisión de las fuentes utilizadas, un estado de la cuestión y, por si fuera poco, la posibilidad de señalar los derroteros teóricos sugeridos. Menuda labor que requiere, sin duda alguna, una selección de aquellas investigaciones que mayores preguntas contengan y cuyos aportes representen una parcela insoslayable para todo el que se anime a estudiar los regímenes autoritarios de los años treinta y cuarenta.

Lamentablemente, todo proceso de selección conlleva una exclusión. Ciertas obras son rezagadas por otras que obtienen la titularidad. Ahora bien, el problema no radica en que deba realizarse una elección, sino en los parámetros a emplear en dicha operación.

Desde mi perspectiva, los estudios de Kenneth Grieb (1979), Erik Ching (2014), Mario Argueta (2008) y la investigación elaborada por Knut Walter (2004) poseen siete atributos infaltables en la labor historiográfica: coherencia, exhaustividad, viabilidad, validez, confiabilidad, innovación cognitiva y, finalmente, riqueza analítica.

La mitad de estas obras no han sido traducidas al español, pero las restantes están disponibles para un público más amplio. A continuación, en aras de cumplir con el balance, analizaré estos trabajos por medio de tres ejes que permiten establecer y comparar la forma en que abordaron su objeto de estudio. Pero antes es conveniente fijar algunas coordenadas biográficas. 
La relación entre esa historia, es decir, entre la interpretación esbozada y el hombre que la formula resulta crucial para orientar al lector de cualquier libro de historia, apuntó Pierre Vilar (1992). Otorga la posibilidad de reconocer ante quién nos situamos. Por esta razón, es preciso examinar su formación académica y los intereses historiográficos que definen su trayectoria. ${ }^{5}$

Un elemento común entre los historiadores seleccionados es su tránsito por las aulas estadounidenses. Kenneth Grieb, fallecido en 2018, cursó estudios en la Universidad de Indiana, donde obtuvo su doctorado en 1966. Mario Argueta, nacido en el departamento de Chimaltenango, Guatemala, hacia 1946 estudió en diversas universidades de la Unión Americana, entre ellas la de Austin, Texas, donde recibió el título de doctor. Knut Walter, mientras tanto, se formó en la Universidad de Chapel Hill, California del Norte, y Erik Ching, el más joven de estos académicos, en la Universidad estatal de California. Este dato podrá parecer baladí; sin embargo — como expondré más adelante—, reviste implicaciones en las interpretaciones elaboradas.

Kenneth Grieb nació en 1939 y desde muy temprano, a la edad de treinta años, empezó la seguidilla de publicaciones que lo llevaron a ser estimado como un especialista de la historia latinoamericana en Estados Unidos. Inauguró su producción con un trabajo sobre Victoriano Huerta y su relación con la Casa Blanca (Grieb, 1969). Y en este derrotero, revisando los documentos del Departamento de Estado, indagó sobre la política exterior estadounidense en la gestión de Warren Harding (1921-1923). Esta obra apareció en 1973, cuando su afán investigativo ya se había orientado hacia Centroamérica y El Caribe.

En noviembre de 1971 se publicó en el Journal of Latin America Studies, de la Universidad de Cambridge, un artículo sobre el ascenso de Martínez. Hasta la fecha es el estudio más completo sobre el tema, donde se muestra el forcejeo entre los funcionarios de Washington y los círculos que apoyaron al general. ${ }^{6}$

\footnotetext{
${ }^{5}$ Georges Duby, historiador de origen francés y de renombre mundial, escribió sobre el papel del historiador y sus imperativos: “Desde hace algún tiempo empleo cada vez más la palabra 'yo' en mis libros. Es mi modo de avisar a mis lectores. No pretendo transmitirles la verdad, sino sugerirles lo probable, colocar entre ellos la imagen que yo me hago honestamente, de verdad. En esa imagen entra en gran parte lo que imagino. He velado, sin embargo, para que las sutilezas de lo imaginario queden sólidamente ancladas. [...] No he olvidado ninguno. Los he comprobado todos minuciosamente con el fin de verificar su firmeza: hablo del documento. Mis pruebas" (Duby, 1991:67-68).

${ }^{6}$ Para el artículo original en inglés véase Grieb (1971:151-172). Una traducción al español se publicó en UCA Editores, El Salvador, durante los años setenta (Grieb, 1978b:243-269). Finalmente, es propicio citar un artículo donde negó la existencia de una liga de dictadores centroamericanos en los años treinta, la cual, según Grieb, obedeció a las acusaciones e inventiva de los exiliados centroamericanos, sobre todo guatemaltecos, radicados en Costa Rica y México (Grieb, 1978a:329-345).
} 
Años más tarde apareció su investigación del ubiquismo. Por medio de estos trabajos, Grieb adquirió un sitial destacado para cualquier historiador que desee hurgar en los archivos con preguntas renovadas.

Una oportunidad similar, referente a la consulta del acervo documental estadounidense, tuvo Mario Argueta. El resultado de esta tarea fue una serie de publicaciones donde la historia hondureña, otrora abordada por abogados y literatos, alcanzó un talante mucho más analítico y fundamentado. Argueta hilvanó una narración fluida, esgrimiendo rutas explicativas novedosas. Entre sus trabajos cabe destacar los siguientes: Los alemanes en Honduras (Argueta, 1991), Historia de los sin historia (Argueta, 1992a), Honduras y lo hondureño en la pluma de Rafael Heliodoro Valle (Argueta, 1992b), Diccionario crítico de obras literarias hondureñas (Argueta, 1993), Pasado y presente de la Secretaría de Gobernación y justicia (Argueta,1998) y Tres caudillos tres destinos (Argueta, 2012). El interés por el pasado hondureño, nación a la que regresó con sus padres luego del derrocamiento de Jacobo Arbenz Guzmán en Guatemala (1954), marcó su quehacer académico. Lustros más tarde comenzó a recopilar la mayor cantidad de libros sobre autores hondureños, actividad que le valió para adjudicarse en tres ocasiones el premio de ensayo Rafael Heliodoro Valle.

Por su parte, los trabajos de Knut Walter y Erik Ching han versado acerca de la historia política salvadoreña. En sus empresas recurrieron a los archivos estadounidenses, pero también al acervo documental centroamericano. Walter, además del libro sobre el régimen que inauguró la dinastía Somoza, ha investigado el tema de la violencia como patrón histórico en El Salvador y la transformación de las fuerzas armadas luego de los Acuerdos de Paz de 1992. Asimismo, ha publicado un estudio sobre las políticas culturales del Estado salvadoreño en 2014.

Erik Ching, entretanto, es autor de artículos, libros y obras conjuntas. Este historiador, miembro del cuerpo académico de la Universidad de Furman, ha analizado la matanza de 1932, el papel del Partido Comunista Salvadoreño (PSC) en dicho evento — citando los archivos de la extinta Unión Soviética-, la memoria histórica sobre los sucesos de 1932, la reforma educativa de los años sesenta y las memorias de la guerra civil salvadoreña acaecida en los ochenta. ${ }^{7}$

Como puede apreciarse, la tarea historiográfica de estos autores incluye distintos temas del siglo XX centroamericano, entre los que sobresalen para el objetivo de este artículo los trabajos sobre los regímenes autoritarios. Acerca de estos,

7 Sobre la matanza de 1932 en El Salvador, que constituyó la respuesta gubernamental a las revueltas originadas en el occidente del país en enero de aquel año, existen dos obras fundantes: Dalton (1972) y Anderson (1982). 
algunas cosas qué apuntar. Por ejemplo, el abordaje sistemático que priva en sus estudios, metodología que evade el carácter personalista de otras obras. Me refiero al prurito de convertir los caprichos presidenciales en explicaciones unívocas de un fenómeno mucho más complejo. Este cambio de perspectiva concede la posibilidad de sopesar las dimensiones de estos regímenes, entramado que abordaré a continuación mediante tres temáticas: primero, el talante providencial con el cual se revistieron los hombres fuertes de Centroamérica en los años treinta; segundo, los mecanismos que emplearon para mantenerse en el poder; y tercero, la relación que sostuvieron con el gobierno de Washington.

\section{El balance historiográfico}

Pues bien, el primer tema concierne al modo providencial con el que ungieron a los hombres fuertes al tomar el poder. Esta condición, reflejo de la inestabilidad política y el surgimiento de sectores que reivindicaron sus derechos, influyó para que los historiadores en cuestión giraran su vista hacia los años veinte. En el libro de Grieb, Walter, Argueta y Ching esta revisión sirve como preámbulo de la eclosión del gobernante salvador de la patria y rectificador del progreso extraviado. En sus páginas aparece un elemento común entre Martínez, Ubico, Carías Andino y Somoza: la experiencia política acumulada al momento de arribar al poder.

Kenneth Grieb revisó el paso de Ubico por distintas jefaturas políticas departamentales y su derrota como candidato presidencial. ${ }^{8}$ Erik Ching, entretanto, procedió de la misma forma: revisando la participación del general Martínez en la campaña proselitista de 1931 y su adscripción al Ateneo en El Salvador. Los otros dos gobernantes, Carías Andino y Somoza, fueron examinados bajo este mismo parámetro. Argueta incluyó en su obra el agitado periplo del abogado que terminó con el grado de general por su involucramiento en la campaña bélica de 1923 (véase foto 3); y nuestro último invitado, Knut Walter, repasó la incursión del general Somoza en la Guardia Nacional y los negocios entablados para forjar un estatus.

\footnotetext{
${ }^{8}$ El estudio de Jean Piel sobre el departamento del Quiché bajo la dictadura liberal brinda insumos para examinar la creación y el funcionamiento de las jefaturas políticas departamentales. Véase Piel (1995). Además, resulta sugerente — para el lector interesado en la figura de Jorge Ubico- la tesis doctoral de Joseph Pitti en la cual examina su labor política y administrativa antes de 1931. Véase Pitti (1975).
} 
Fuente: La Tribuna, 12 de marzo de 2017, p. 15.

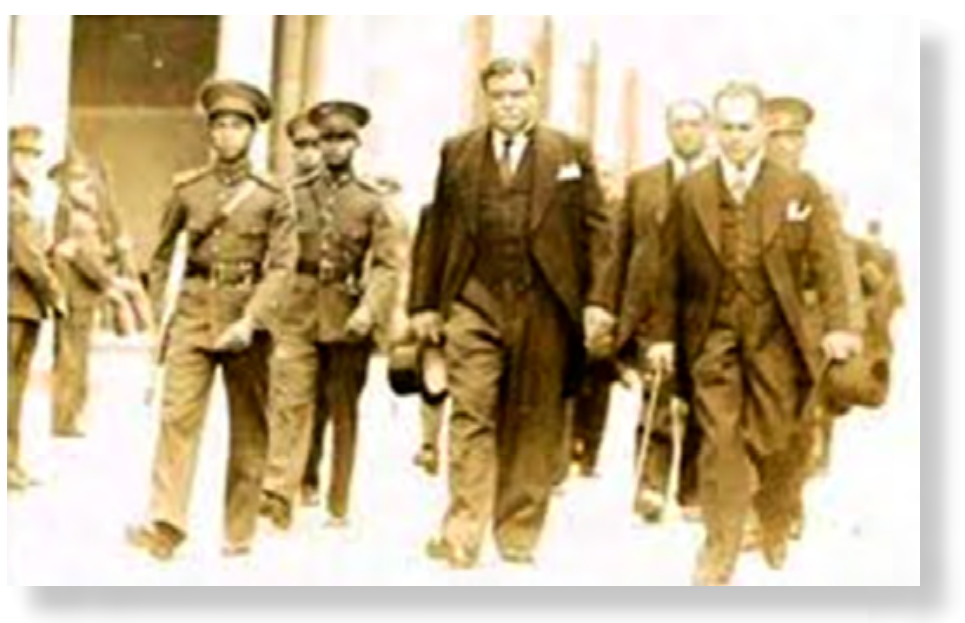

Foto 3. Tiburcio Carías Andino.

Ahora bien, más allá de estas particularidades es preciso preguntar: ¿por qué revisar los años previos? ¿Por qué examinar los antecedentes de estas figuras políticas? Desde mi postura un estudio de este tipo visualiza las alianzas que urdieron estos cuadros y los grupos que los acuerparon, para definir su destino político. Se trata, por lo tanto, de un aspecto nada desdeñable, sobre todo cuando se estudian regímenes que surgieron de la crisis económica, la efervescencia social y las luchas fratricidas que acechaban las bases de las repúblicas oligárquicas construidas en el siglo XIX.

No obstante, ¿estamos ante caudillos que irrumpieron como fue habitual en la región luego del estallido de crisis variopintas? ¿Nos hallamos, entonces, ante los últimos caudillos del siglo XX centroamericano? La duda no existió en el caso de Grieb, quien anotó en el título de su obra esta categoría: Guatemalan caudillo. Erik Ching, mientras tanto, anotó sobre la figura de Martínez en sus conclusiones: "Su persona se ubica en una encrucijada, entre las oligarquías civiles del siglo XIX y los regímenes autoritarios del siglo XX» (Ching, 2007:184). Mario Argueta despejó el camino y respondió de manera afirmativa a las preguntas planteadas. Según este historiador, Carías Andino reunió, entre otros atributos de los caudillos del continente, sus antecedentes militares, astucia, determinación y coraje personal. Además, su estilo de gobernar exacerbó la adhesión a un jefe del que proviene la recompensa o el castigo (Argueta, 2008:109). Knut Walter, finalmente, empleó un tono semejante al citar el provecho que Somoza extrajo del viejo orden caudillista en su candidatura presidencial de 1936 y el funcionamiento del Partido Liberal (Walter, 2004:82). 
Quiero centrarme ahora en un aspecto que se conecta con la segunda temática planteada. En efecto, si estamos ante caudillos y por caudillismo se entiende un sistema de lealtades, de fuerza militar, autoridad y protección (Hall, 2014:161 ), entonces es preciso examinar cómo preservaron el poder valiéndose de una base personal. "Porque soy somocista o martinista», fue la explicación escrita en los afiches del partido oficial de la dinastía y en el carné de los cuadros del Partido Pro-Patria en El Salvador. Sin duda, la figura del líder en el poder —como prefieren Ilamarlo los teóricos de los regímenes autoritarios (Morlino, 2005)_ adquirió relevancia, pero sus mecanismos para mantenerse ahí nos obligan a dirigir nuestra mirada hacia otros actores políticos. Esta, precisamente, es una de las virtudes de los trabajos examinados. El estudio del caudillismo no impidió establecer las dimensiones del régimen, donde aparecen como protagonistas el partido oficial, la oligarquía, las empresas trasnacionales y las redes clientelares. El poder fue sostenido por dispositivos o estrategias analizados por los historiadores.

En estas líneas me refiero a tres mecanismos que marcaron el funcionamiento del régimen y constituyen un punto común de su estudio. Primero, las prerrogativas concedidas a algunos sectores de la población a cambio de su colaboración en la represión y el espionaje. Segundo, la violación del principio constitucional de la división de poderes. Y tercero, el uso indiscriminado y reiterado de la represión. El abordaje sucinto de estos dispositivos permite sostener que la violencia fue utilizada, pero no constituyó el recurso exclusivo.

Inicio esta exposición con la red clientelar organizada por los regímenes. Programas sociales, incorporación a una burocracia en crecimiento y el ejercicio de la violencia — como fue el caso de la Guardia Cívica en El Salvador- representaron las concesiones a cambio de la anulación de cualquier signo opositor. Al respecto, son bastantes los archivos citados en que se constatan estas prerrogativas y se trasluce una tendencia de la historia política centroamericana: el papel determinante de las redes clientelares desde el siglo XIX.9 Por lo tanto, los regímenes autoritarios retomaron exitosamente este dispositivo. Nada nuevo bajo el sol y menos cuando examinamos el corporativismo de los poderes estatales. Por cierto, faltaría revisar el segundo mecanismo.

Puede sorprender a quien estudia por primera vez la historia política centroamericana el hecho de que las elecciones hayan sido frecuentes en los años treinta

\footnotetext{
${ }^{9}$ Héctor Pérez Brignoli, en su artículo sobre los levantamientos de 1932 en El Salvador, señaló este aspecto. Examinó las cofradías indígenas en el occidente del país, estableciendo — como se muestra en los archivos - su participación como base clientelar de diversos movimientos y figuras políticas antes de las rebeliones (Pérez, 2001).
} 
y cuarenta. Por supuesto, en mayor medida las legislativas: ante el continuismo presidencial forjado por los diputados y la suspensión de la autonomía municipal. Los cabildos abiertos y las manifestaciones orquestadas por los alcaldes marcaron estos eventos. Durante estas fechas la población externó su simpatía por el gobernante en turno y solicitó, a través de cartas dirigidas al ministro de Gobernación, la continuidad de la empresa oficial. Desde Concepción de Ataco, departamento de Ahuachapán, el edil comunicó a sus superiores: «Con gran entusiasmo efectuose [sic] manifestación pública en honor de nuestro mandatario supremo, general Martínez, asistieron numerosos afiliados al Partido Pro-Patria». ${ }^{10}$

En otras palabras, la actividad política siguió su curso, pero dirigida por los personeros gubernamentales y los elementos del partido oficial. Uno y lo mismo en la Asamblea Nacional, órgano establecido en las Constituciones decimonónicas como la palestra donde las diversas expresiones políticas tendrían representación. Al respecto, los trabajos revisados muestran con claridad la violación del principio de separación de los poderes del Estado, elemento básico del liberalismo moderno bajo el cual se estipularon también las garantías individuales. Los autores exponen, para explicar mejor este aspecto, una faceta establecida por Antonio Acosta, quien, al estudiar la formación de la burguesía salvadoreña durante el siglo XIX, manifestó:

la oligarquía simplemente copió los principios de las nuevas constituciones burguesas, manteniendo en gran medida las relaciones heredadas de la colonia, frenando así la evolución de las estructuras políticas. Era una profunda contradicción que conduciría a la larga a graves problemas en la vida social y política (Acosta, 2013:17).

En efecto, ingentes vicisitudes en sociedades que encararon múltiples trastornos políticos después de los años cuarenta; pero a la vez representó una tendencia y condición aprovechada por los gobiernos autoritarios examinados. Ching expuso cómo la Corte Suprema de Justicia se plegó a los designios continuistas del general Martínez. Kenneth Grieb analizó la composición del Congreso y su labor complaciente con las directrices del Partido Liberal Progresista. Walter revisó las convenciones del Partido Liberal Nicaragüense, a las cuales concurrían los diputados para preservar la línea oficial en el órgano legislativo. En síntesis, los tres poderes del Estado se encontraban en plena consonancia, legalizando las

10 Telegrama del alcalde de Concepción de Ataco, Ahuachapán, dirigido al ministro de Gobernación, Ahuachapán, 11 de julio de 1943. En Archivo General de la Nación de El Salvador, fondo Maximiliano Hernández Martínez, correspondencia, Exp. 15. 
decisiones del Ejecutivo. En 1944, luego de las protestas suscitadas en Honduras, el congreso corroboró su talante corporativo. Declaró a Carías Andino fundador y defensor de la paz y, por si fuera poco, le proporcionó permiso para aceptar la Orden Cristóbal Colón, entregada por Leónidas Trujillo, su homólogo dominicano. En síntesis, la legalidad en su faceta formal estaba garantizada y cuando esta fue cuestionada, los regímenes tuvieron sus aliados potenciales en los cuerpos de seguridad, los auxilios civiles y el ejército.

El tercer y último mecanismo que los regímenes autoritarios utilizaron para sostenerse en el poder atañe directamente a la represión. Insuficiente para preservar la banda presidencial, pero insoslayable para acallar las críticas e infligir castigos ejemplares. Estos últimos casos fueron abordados en el trabajo de Ching y Grieb. Ubico y Martínez inauguraron sus gobiernos sembrando el terror y persiguiendo a su enemigo fundante: el comunismo. La matanza de 1932 sentó precedentes en suelo salvadoreño. Por un lado, acabó la participación política instaurada en el mandato de Pío Romero Bosque (1927-1931) y, por otro, erigió la preservación del orden como prioridad. El martinato se adjudicó un respaldo contundente de los sectores oligárquicos, agroexportadores y terratenientes; recursos que Ubico también convocó «antes que la agitación política tomara las proporciones de El Salvador» (Taracena, 1989:60 ). Luego de la persecución desatada a finales de 1931, un sistema de vigilancia articulado prevaleció en Guatemala. "Se trató de espiar y restringir las actividades de todos los ciudadanos, y la vigilancia policíaca se extendió por doquiera, hasta imposibilitar el ejercicio de cualquier oposición» (Grieb, 1996:55).

En Honduras y Nicaragua la tónica fue similar. Argueta examinó la represión hacia los disidentes, así como sus actividades conspirativas en las naciones vecinas y México. En el capítulo noveno, dedicado a la oposición, el historiador expuso el malestar que produjo la reelección de Carías en 1936. Además, el éxodo de opositores que sobrevino ante el temor de pudrirse en las cárceles del régimen. De hecho, «en marzo de 1936, se calculaba que en Nicaragua se encontraban dos mil emigrados, quinientos en Belice, mil en El Salvador y doscientos en Costa Rica» (Argueta, 2008:271). Al explicar la contundencia del régimen en esta empresa, Argueta aludió a uno de los actores de este tercer mecanismo: el ejército.

No parece haber ninguna oportunidad de cambio de gobierno en Honduras en el futuro cercano -informó el agregado naval estadounidense en los años cuarenta-. El presidente Carías tiene el apoyo completo del ejército... los comandantes son leales 
a Carías, ya que disfrutan de cierto peculado en el control de sus respectivos distritos (Argueta, 2008:114-115).

Somoza y uno de sus principales aliados, la Guardia Nacional, no tuvieron nada que envidiarle al régimen hondureño. Sereno, astuto y calculador, Somoza encabezó un engranaje mediante el cual mantuvo a raya a la oposición leal y reprimió a los que objetaron su continuismo. Para los primeros, como afirmó Walter, el régimen dispuso cargos oficiales o recursos económicos para el funcionamiento de la Casa del Obrero. ${ }^{11}$ Hacia los desleales, entretanto, apuntaron sus armas legales, tales como la Ley Marcial de 1939 y la Ley de Defensa de la Democracia en 1941. En el cumplimiento de estas medidas, el régimen invistió a los jueces de mesta, cargó que recayó en campesinos con poca escolaridad y buenas relaciones con el partido oficial. Estos deambulaban «en lugares públicos supuestamente para enterarse de lo que decían conversadores, comunistas y liberales anti-somocistas acerca de la situación política» (Walter, 2004:179) (véase foto 4).

Fuente: La Prensa, 17 de septiembre de 2017, Nicaragua.

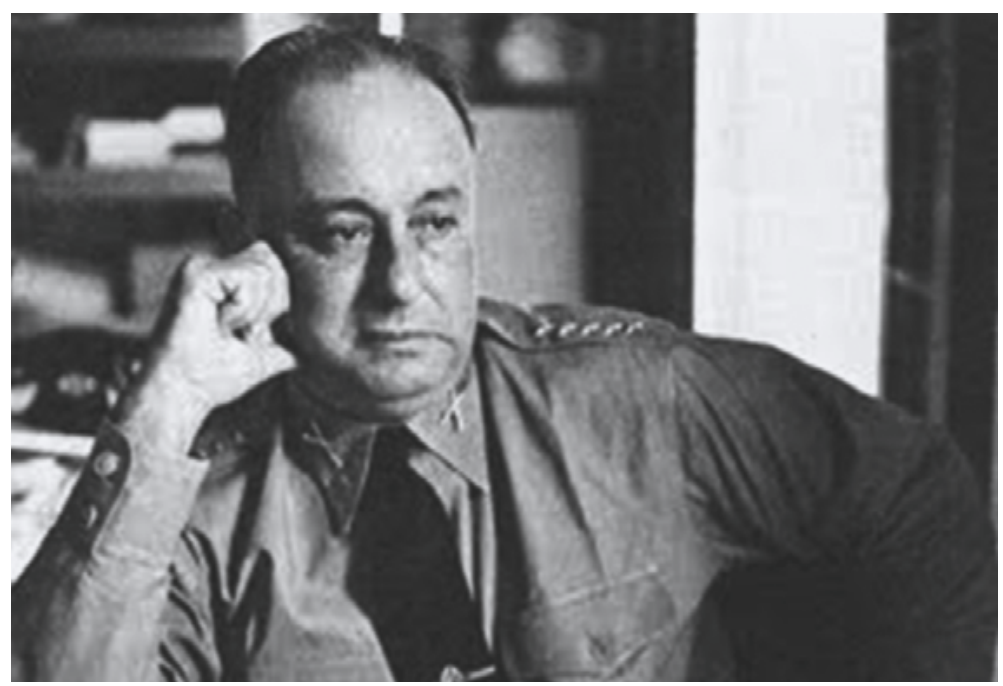

Foto 4. Anastasio Somoza (1936-1956).

\footnotetext{
11 "Somoza redactó un estatuto para la administración y el funcionamiento de la Casa del Obrero, que en buena medida restringió sus actividades a las de un club social. El estatuto prohibía las discusiones políticas o religiosas, lo mismo que toda actividad o propaganda comunista o de sistemas totalitarios y en general de opiniones contrarias al orden público. [...] Cabe señalar que, según el informe financiero de las actividades de la Casa del Obrero del año 1942, más del 91\% de todos los gastos correspondieron a compra de licor y fiestas, mientras que sólo un $6.4 \%$ fue dedicado a actividades culturales y asistencia social" (Walter, 2004:165).
} 
Represión, espionaje, prerrogativas y violación artera del principio de la división de poderes son algunos de los mecanismos que se mencionan en las obras revisadas, en cuyas líneas se problematiza el continuismo desde un enfoque multicausal. Aquí revistió importancia la propaganda oficial, todas las alianzas entabladas con la oligarquía y hasta un contexto internacional propicio para este tipo de estratagemas. Este último elemento nos conduce al terreno de las relaciones exteriores, donde el vínculo con el gobierno estadounidense resulta de especial relevancia. Los regímenes autoritarios, al paliar los efectos de la crisis económica, forjaron la estabilidad política que Washington precisaba en el epílogo de los años treinta.

En páginas anteriores, al exponer la formación de los autores elegidos hice alusión a un punto que tienen en común: la citación abundante de los archivos estadounidenses. Eric Ching, por ejemplo, revisó las presiones que el Departamento de Estado ejerció de forma infructuosa para expulsar a Martínez del poder. En su afán, los funcionarios recurrieron al Tratado de Paz y Amistad de 1923. Mediante sus cláusulas, los firmantes se comprometieron a negar su reconocimiento diplomático, bajo la vigilancia de Washington, a todo grupo que asaltara el poder por medio de un cuartelazo. Durante los años veinte, Estados Unidos desplegó este recurso para garantizar la estabilidad política de la región. Pretendieron evitar la entronización de caudillos y promover la celebración de elecciones libres. Buscaron, asimismo, asegurar los intereses de las empresas de esta nación (Handy, 1996) y exterminar las luchas intestinas que sangraban las arcas del Estado (Munro, 2013). Dos militares que asestaron sendos cuartelazos vieron frustrados sus anhelos en Costa Rica y Guatemala. Sin embargo, esta manera de conseguir la estabilidad del istmo fue relegada en los años treinta. ${ }^{12}$

Como se muestra en los trabajos aludidos, el arribo de los demócratas a la Casa Blanca en 1933, con Franklin D. Roosevelt a la cabeza, suscitó la entrada en vigencia de la política del buen vecino. Bajo este esquema, los funcionarios del Departamento de Estado asumieron una forma novedosa de relacionarse con los gobiernos latinoamericanos. La no intervención en sus asuntos domésticos fue el

\footnotetext{
12 Kenneth Grieb, en su artículo sobre el ascenso de Martínez, mostró la pérdida de efectividad del Tratado de 1923 como recurso coercitivo cuando no estaba acompañado de la intervención militar estadounidense. "En conclusión —escribió este autor_, cuando el levantamiento [de 1932] solidificó su base interna, el líder salvadoreño percibió que podía, en forma segura, arriesgarse ante el desagrado del coloso norteño" (Grieb 1978b:269). Erik Ching, mientras tanto, expuso el parecer del secretario de Estado de los Estados Unidos, Henry Stimson, ante esta situación: "El hombre que... es el único pilar frente al triunfo de lo que parece ser una desagradable revolución proletaria... [pero] no estamos en capacidad de reconocerlo bajo lo acordado en 1923" (Ching, 2007:145)
} 
estandarte, aunando esfuerzos por vitalizar los lazos panamericanos. Tambores de guerra sonaron desde Europa y, ante la posibilidad de una nueva guerra mundial, los Estados Unidos optaron por la cohesión del continente americano y la protección de zonas neurálgicas en materia geopolítica.

Centroamérica, en este sentido, adquirió muchísima importancia. Washington destinó recursos económicos, asesoró a los ejércitos del área y mejoró las carreteras con el objetivo de proteger el canal de Panamá. Sin embargo, el giro de la política exterior estadounidense generó una paradoja: estrechó vínculos con regímenes autoritarios. La ideología democrática probó ser una arenga dirigida contra las potencias del Eje, mas no al territorio centroamericano. Argueta ilustró esta paradoja por medio de un documento del Departamento de Estado: «No parece haber ninguna duda de que los aviones del gobierno, piloteados por ciudadanos americanos, son las armas más efectivas que tiene el gobierno en el mantenimiento del orden interno y la supresión de revoluciones incipientes» (Argueta, 2008:117).

En consecuencia, y como se exhibe en los trabajos citados, los gobernantes centroamericanos tuvieron en Washington un aliado trascendental. Mantener el orden y la estabilidad política de la región era una prioridad ante la beligerancia que los regímenes fascistas exhibían en Europa. En medio de este escenario Carías Andino cambió su postura de los años veinte: cuando atisbó en las empresas bananeras la fuente de la expoliación en Honduras, y optó por la colaboración estrecha con los inversionistas extranjeros. Jorge Ubico, mientras tanto, marchó siempre de la mano de Washington, convirtiendo su gobierno, incluso, en uno de los primeros en declarar la guerra a Japón en 1941. Martínez, por su parte, no se rezagó en el tema. Permaneció anuente a la injerencia en la economía salvadoreña de un representante de los bancos estadounidenses (Lindo, 2015) y destituyó del gabinete a los militares que Washington reputó como simpatizantes del fascismo. ${ }^{13}$

${ }^{13}$ William Renwick fue el representante fiscal de los bancos estadounidenses en El Salvador. Llegó al país en febrero de 1923, luego de que el Estado adquiriera un empréstito, y permaneció por dos décadas, convirtiéndose en guardián de la más estricta ortodoxia económica, según Héctor Lindo Fuentes. "El dictador Martínez — manifestó Lindo_-, a pesar de su pretendida independencia, se aseguró que Renwick participara en todas las decisiones económicas importantes de su administración" (Lindo, 2015). Para un análisis de la situación económica imperante en el gobierno del general Martínez, donde se incluye un estudio de las consecuencias de la crisis económica de 1929 en El Salvador véase Wilson (2004:201-224). En Nicaragua las aduanas fueron intervenidas por un coronel estadounidense, quien fungió como agente fiscal para asegurar el pago de la deuda a los bancos de esta nación. 
Finalmente, sobre el somocismo en su primera etapa no existe material que apuntar en otra dirección. Desde 1936 hasta 1956, los veinte años en que Somoza García ejerció el poder, los gobiernos estadounidenses integraron el sistema político y fueron -como escribióWalter-«una variable importante en los desenlaces políticos dentro del país» (Walter, 2004:387). El caso nicaragüense resulta llamativo desde la contradicción referida, porque la política de no intervención fortaleció los elementos más duros del régimen, entre ellos la Guardia Nacional. Escrito en otras palabras, el alejamiento de los estadounidenses una vez puestas las bases de la dictadura otorgó «carta blanca a Somoza, quien procedió a materializar sus ambiciones sin temor de una reacción estadounidense» (Walter, 2004:387). Volker Wünderich, autor de una de las biografías más sólidas de Sandino, sintetizó la paradoja generada tras el ascenso y consolidación del primer Somoza:

la intervención militar se había justificado con la pretensión de permitir que el país pudiera disfrutar la democracia y tuviera elecciones libres. Ahora que el presidente Sacasa, elegido democráticamente, se hallaba bajo presión de la Guardia Nacional, creada por Estados Unidos, se hubiera requerido una nueva intervención para proteger al país contra la dictadura. Pero el ministro Lane rechazaba esto, indignado, en nombre de la no intervención (Wünderich, 2009:375).

En síntesis, una reconstrucción providencial de los hombres fuertes, su ascenso al poder y las relaciones con el gobierno estadounidense son algunos de los temas en común de las obras elegidas. Las cuatro arrojan un panorama sugerente de los regímenes autoritarios y su tiempo. Además, poseen rasgos distintivos que es necesario señalar. El primero atañe al abordaje del escenario regional, en concreto a las relaciones entre los regímenes autoritarios. Grieb y Argueta sobresalen en este renglón, pues también expusieron los pactos y resquemores de los gobernantes hacia sus vecinos.

Esta afirmación no significa que los autores restantes hayan descuidado esta arista, pero es innegable que la ubicaron en un plano periférico. Argueta y Grieb, por el contrario, llegaron incluso a plantear tesis contrapuestas. El primero sostuvo que los caudillos firmaron pactos que sirvieron para controlar a sus opositores. Grieb, entretanto, desestimó el mito de una liga de dictadores centroamericanos y fue más allá al expresar que el entramado imperante, lejos del buen entendimiento, estuvo plagado de suspicacia y reyertas subterráneas. ${ }^{14}$ Puntos discor-

\footnotetext{
14 "Los incidentes producidos por las rivalidades nacionales históricas siguieron su curso en los años treinta —escribió Grieb-. Sin duda, hubo cierta cooperación transitoria, pero esta apenas
} 
dantes que, sin duda, serán materia de investigaciones ulteriores y que aparecen también en los trabajos de Erik Ching y Knut Walter. El primero, más orientado hacia la historia política, utilizó la categoría de clientelismo para revisar el funcionamiento del martinato. Con base en esta metodología, portadora de un diálogo entre la tarea historiográfica y las ciencias sociales, el autor abonó un elemento capital, a saber, una concepción de la política como mosaico de alianzas dispersas por medio de toda la nación, producto de una relación entre los niveles de gobierno local, regional y nacional (Ching, 2007).

Knut Walter, por su parte, examinó las alianzas fraguadas durante la primera parte de la dinastía somocista, pero con mayor énfasis en el plano económico. El poder de Somoza García y su habilidad para interpretar las intenciones de los Estados Unidos y actuar conforme a ellas resultan inteligibles cuando se toma en consideración que también fue empresario, integrante de una red de negocios que tuvo su baluarte en el sector agroexportador.

Pues bien, asistimos mediante la lectura de estas obras a la exposición de peculiaridades de los procesos nacionales, al establecimiento de puntos en común y a distinguir algunas tesis contrapuestas. Las investigaciones traslucen aportes en la historia política, social y económica. Son portadoras de las intrigas del poder, de las estrategias que estos regímenes ejecutaron para mantenerse a flote y fraguar la reelección. Además, sus páginas permiten enfocar perspectivas de investigación, rutas temáticas más profusas e interpretaciones renovadas. Y precisamente en el establecimiento de algunas de éstas centraré mi atención en el apartado siguiente.

\section{Perspectivas de investigación}

Hace pocos años, a consecuencia de una campaña internacional por transparentar la administración gubernamental, se aprobaron leyes de acceso a la información pública en Centroamérica. En su marco normativo aparecieron como obligatorios los siguientes puntos: primero, la organización y los plazos de conservación de la documentación producida y, segundo, la instalación de oficinas de información y atención al público en general. La adopción de estos lineamientos, donde otrora reinaba el sectarismo y la negligencia ante cualquier consulta, tiene repercusiones en la tarea historiográfica. Hay fondos documentales, en pro-

constituyó una alianza. Tales acciones reflejaron una conveniencia temporal, y representaron un reconocimiento de la realidad que se produjo solo después de o entre intentos repetidos por ayudar a los revolucionarios" (Grieb, 1978a:344 [traducción mía]). 
ceso de organización, a disposición de los investigadores. Archivos municipales, de relaciones exteriores y economía, entre otros, brindan insumos para formular interpretaciones novedosas del pasado reciente de la región. Y esta posibilidad, que conlleva una labor de búsqueda y sistematización, se relaciona con la temática abordada en el presente artículo.

Hasta el momento las fuentes primarias estadounidenses prevalecen en las obras sobre los regímenes autoritarios de los treinta y cuarenta. ${ }^{15}$ Su relevancia no se pone en discusión. Se trata de una perspectiva determinante para explicar los vaivenes políticos de la centuria pasada. No obstante, su uso exclusivo tiene, en mi parecer, dos implicaciones: la reconstrucción del pasado considerando una sola posición, una visión de los problemas y, segundo, la clausura de resquicios y fisuras que permiten esbozar las siguientes preguntas: ¿es que los diplomáticos estadounidenses manipularon todos los hilos de la política regional? ¿Acaso los regímenes estudiados no actuaron de forma subrepticia para eludir el lente de Washington? Un ejemplo ayudará a clarificar este punto. Kenneth Grieb escribió de forma concluyente en el artículo sobre una liga de dictadores centroamericanos:

En realidad, la relación entre los hombres fuertes centroamericanos, mutuamente sospechosos y siempre ambiciosos, se caracterizó por constantes maniobras de contención en lugar de alianzas o cooperación. El surgimiento de una serie de caudillos no erradicó las rivalidades nacionales tradicionales en el istmo, y cada uno de los líderes encontró que era necesario y conveniente operar dentro de sus exigencias domésticas (Grieb, 1978a:336 [traducción mía] ).

El historiador acertó en señalar las disputas y suspicacias entre los gobernantes en turno; pero nos quedó a deber cuando atribuyó un estatuto preliminar a la cooperación entre estos. Grieb, en efecto, sustentó su tesis en los archivos del Departamento de Estado y algunos legajos del Archivo General de Centroamérica. Sin embargo, al consultar los expedientes disponibles en el Archivo Histórico de Relaciones Exteriores de El Salvador quedó en evidencia la cooperación con el ubiquismo. En agosto de 1935, los personeros salvadoreños enviaron un documento a sus vecinos donde citaron las actividades que habían realizado para la tranquilidad del régimen. Vigilancia estrecha, detenciones y ex-

\footnotetext{
${ }^{15}$ Debo aclarar que existen variaciones en los trabajos elegidos. Walter y Ching citaron abundante material de archivo centroamericano; Argueta en menor medida y Grieb, alejado de los anteriores, basó sus indagaciones en los fondos documentales estadounidenses.
} 
pulsión de los disidentes guatemaltecos más problemáticos definieron el contenido de esta comunicación:

Don Francisco Nájera Andrade o Federico González, ingresó a El Salvador el día 28 de noviembre de 1932, por Candelaria de la Frontera, procedente de Guatemala, en calidad de emigrado político. Desde su llegada se le nombró servicio de vigilancia estrecha a cargo de agentes de Investigaciones por espacio de varios meses. Además, se le ordenó presentarse a la Sección de Investigaciones Especiales tres veces al día, así: por la mañana, por la tarde y por la noche. El servicio de vigilancia fue encomendado a dos agentes que le seguían sus pasos. Finalmente, se le ordenó desocupar el país, lo que verificó inmediatamente, saliendo por el puerto de La Unión el día 2 de agosto de 1934, con prohibición de volver a territorio salvadoreño. ${ }^{16}$

El informe trasluce, además de los recursos usados en el control de los exiliados, la vigilancia prolongada de este cuadro y otros que aparecen señalados. Ante esta evidencia cabe entonces preguntar: ¿acaso este documento no prueba que fue entablada la cooperación sin la necesidad de formar una liga de dictadores? Los agradecimientos del ubiquismo y la promesa de retribuir estas acciones cuestionan la tesis de Grieb. Al respecto, puede sostenerse que la suspicacia fue relegada cuando el bienestar común estuvo en juego. Y aún más cuando emergió una situación que amenazaba el statu quo edificado durante los años treinta. Como ejemplo de lo anterior puede citarse el respaldo que Somoza ofreció a Martínez cuando un grupo de civiles y militares se alzaron en armas en la Semana Santa de 1944. "Señor presidente Somoza reitera ofrecimiento al presidente Martínez su decidida cooperación en la forma que indique. Pertrechos fuerza aérea listos». ${ }^{17}$

La investigación sobre este tema puede ampliarse al responder las siguientes preguntas: ¿Qué información referente al tema existe en los archivos centroamericanos? ¿Cuál fue el papel adoptado por el gobierno de Costa Rica y Panamá ante las dictaduras del istmo? Se requieren, como puede observarse, investigadores que hurguen los archivos que Grieb no pudo consultar. Urgen trabajos

\footnotetext{
${ }^{16}$ Memorándum de disposiciones tomadas por el gobierno de El Salvador en favor de la tranquilidad de Guatemala y su Gobierno. San Salvador, agosto de 1935. En Archivo Histórico del Ministerio de Relaciones Exteriores de El Salvador. Asuntos políticos y de Gobierno en general, 1935.

17 Decodificación de telegrama del embajador salvadoreño al ministro de Relaciones Exteriores de El Salvador, Managua, jueves 6 de abril de 1944. En Archivo Histórico del Ministerio de Relaciones Exteriores de El Salvador, asuntos políticos, 1944, tomo XIV.
} 
donde el escenario regional sea sometido a un análisis minucioso, trascendiendo el plano nacional para continuar estableciendo los elementos comunes y las peculiaridades. ${ }^{18}$

Por otro lado, es pertinente seguir analizando la coalición dominante de los regímenes autoritarios. Por ejemplo, el papel de la Iglesia católica y los grupos conservadores que, como en el caso de El Salvador y Guatemala, defendieron el anticomunismo para poner punto final a las reivindicaciones de los grupos que surgieron en los años veinte. En este punto, la investigación de Juan Pablo Gómez, quien rastreó el surgimiento del Movimiento Reaccionario y el respaldo que brindaron a Somoza García, alcanza un estatuto encomiable (Gómez, 2015). Aunque para ser justo los primeros pasos en el caso salvadoreño han sido dados por Rafael Lara Martínez al examinar el silencio y apoyo de ciertos intelectuales al martinato (Lara, 2011; 2013).

Las obras analizadas constituyen, a su vez, un incentivo para dilucidar una temática descuidada en la historiografía centroamericana: las actividades de los grupos fascistas en la región y la relación de los gobiernos autoritarios con los de Franco y Mussolini en los treinta. Sobre el tema aparecen indicios en los archivos, periódicos y publicaciones recientes (Taracena, 2017). Pienso, como modelo a emular, en el trabajo de Luigi Calò Carducci sobre el Perú, donde examinó el proceder de un gobierno que, sin tener una influencia marcada como Argentina o Brasil, vivió una luna de miel con el fascismo italiano (Calò, 2007). ¿Por qué Ubico y Martínez fueron de los pocos gobernantes que reconocieron al régimen de Francisco Franco? La pregunta, ciertamente, sienta rutas de investigación (véase foto 5).

Finalmente, quiero abordar el tema con el cual inicié este artículo: el accionar de los exiliados en Costa Rica y México. Sobre el particular se han publicado aportes valiosos en territorio costarricense. La figura de Vicente Sáenz, por ejemplo, se ha estudiado por los rasgos de su ajetreada actividad política e intelectual como opositor a las dictaduras del istmo (Lopes, 2013). Empero, poco se han investigado aspectos de la agrupación que encabezó en México: la Unión Democrática Centroamericana (UDCA). ¿Construyó alianzas con sectores progresistas de esta nación? ¿Cuál fue su relación con los gobiernos mexicanos? ¿Por qué se disolvió este colectivo?

\footnotetext{
${ }^{18}$ Sobre todo, cuando se considera que la cooperación entre gobiernos prosiguió en los años cincuenta y sesenta. Es el caso de la Organización de Estados Centroamericanos, odeca, y más tarde, cuando la guerra fría arribó a la región, el Consejo de Defensa Centroamericano, CONDECA. De hecho, se ha escrito muy poco acerca de estos esfuerzos conjuntos.
} 
Fuente: Turcios, 2000:413.

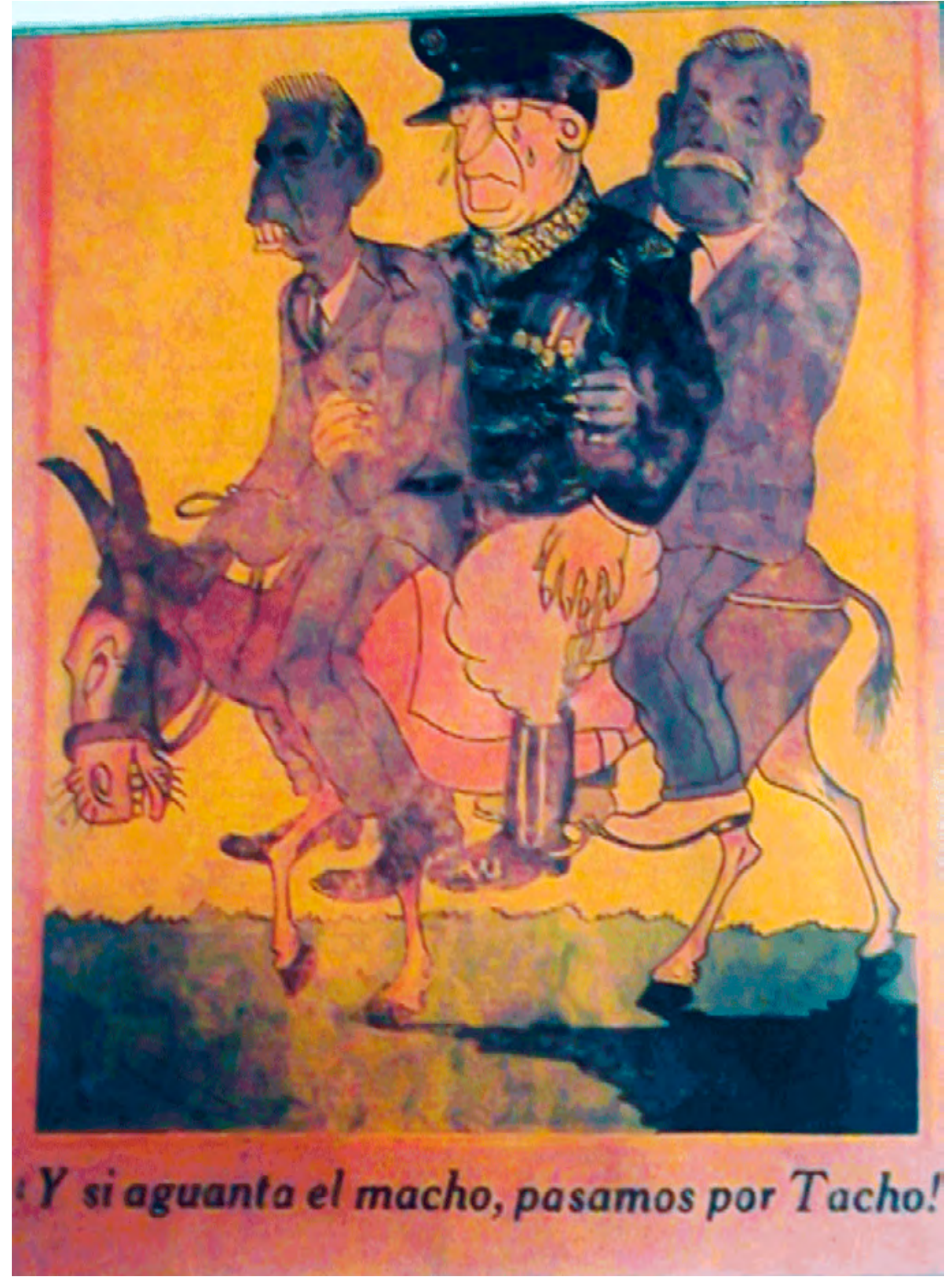

Foto 5. Caricatura alusiva al derrocamiento de Martínez en El Salvador.

Asimismo, aparece entre los pendientes el quehacer de aquellos exiliados ajenos a la UDCA — sobre todo durante los años treinta, cuando los planes conspirativos tomaron auge- cuya estancia en México distó mucho del relajamiento y el conformismo. Antes bien, sus actividades motivaron los mensajes de reclamo citados al principio de este recuento, mediante los cuales se denunciaba por 
parte de los regímenes aludidos las facilidades que se les otorgaban en México. El gobierno mexicano tomó cartas en el asunto, pero decidió apagar el incendio sin eliminar sus pavesas. A principios de 1944 se encomendó al Departamento de Investigaciones Políticas y Sociales, de la Secretaría de Gobernación, la siguiente tarea: «Se servirá usted practicar discreta investigación, sobre un manifiesto en contra del señor Anastasio Somoza, actual presidente de la República de Nicaragua, que ha sido fijado en las principales calles de la ciudad». ${ }^{19}$

¿Qué disposiciones adoptó el gobierno mexicano con estos disidentes? ¿Constituyeron un verdadero peligro para los regímenes centroamericanos? ¿Los favoreció el gobierno presidido por Lázaro Cárdenas emulando las acciones de Plutarco Elías Calles con Sacasa en Nicaragua? ¿Tejieron alianzas los exiliados con grupos de la sociedad civil mexicana? ¿Tuvieron algún tipo de apoyo en sus países de origen? Muchas preguntas por responder y archivos que consultar. Afortunadamente.

\section{Consideraciones finales}

Citados en diversas obras que abordan el siglo XX centroamericano, los regímenes autoritarios instaurados durante los años treinta han adquirido significados contrapuestos. Desde la visión de sus simpatizantes, estos combatieron con aplomo las secuelas de la crisis económica de 1929, preservaron el orden y edificaron obras de infraestructura que vitalizaron la actividad comercial del país. Dictaduras sí, pero con un estilo patriarcal, afirmó Guerra Kampy al hablar del general Martínez. Miel sobre hojuelas que otros rechazaron en sus interpretaciones. Para estos cuadros los gobiernos en cuestión escribieron una página negra de la historia regional. Inauguraron el periodo de la dictadura militar represiva, y con su reelección denostaron los preceptos constitucionales. Las posturas reseñadas expresan la pasión que ha palpitado en torno a la figura de Ubico, Martínez, Carías y Somoza. Pasión que puede desplegarse en el ámbito historiográfico con pretensiones ajenas al maniqueísmo.

Esta es una de las virtudes de los trabajos seleccionados. Los autores no dedicaron sus párrafos a defender o atacar, sino a explicar un episodio de la historia política centroamericana. Los textos combinan teoría, conceptos, narrativa, fuentes y una metodología para forjar un resultado. Se trata de interpretaciones,

\footnotetext{
${ }^{19}$ Comunicación del jefe del Departamento de Investigaciones Políticas y Sociales a un inspector de dicha entidad. En Archivo General de la Nación de México. Secretaría de Gobernación. Siglo XX. Caja 18-022.
} 
por supuesto, pero mucho más esforzadas y fundamentadas. La creatividad del historiador está implícita y hasta su postura ideológica. Además, con una gran ventaja: exhiben los documentos que respaldan al escribiente en su andanza. Esta forma de proceder, propia del quehacer historiográfico profesional, condujo a la selección de sus trabajos sobre los regímenes autoritarios y el establecimiento de similitudes y diferencias en su abordaje.

Entre las primeras examiné los mecanismos que permitieron a los gobiernos sostener el poder por más de un decenio, allende las claras diferencias sociales, políticas y económicas de los países centroamericanos. El clientelismo político, la violación del principio de división de poderes, la represión y el apoyo estadounidense fueron erigidos por los autores como sus pivotes. Asimismo, establecí entre sus discordancias el estudio del escenario regional, donde existen tesis contrarias en cuanto a las alianzas tejidas entre los gobernantes. En síntesis, estas obras constituyen piezas claves de la historiografía centroamericana y sus tesis, basadas en su mayoría en archivos estadounidenses, un incentivo para investigaciones ulteriores.

\section{Fuentes de consulta}

\section{Fuentes primarias}

Archivo General de la Nación de El Salvador

Archivo General de la Nación de México

Archivo Histórico Genaro Estrada. Secretaría de Relaciones Exteriores de México

Archivo Histórico del Ministerio de Relaciones Exteriores de El Salvador

\section{Periódicos}
La Prensa
La Tribuna
Prensa Libre
El Día

Acosta, Antonio, 2013, Los orígenes de la burguesía de El Salvador: el control sobre el café y el Estado, 1848-1890, Sevilla, Aconcagua Libros.

Anderson, Thomas, 1982, El Salvador, 1932, San José, Educa.

Argueta, Mario, 1991, Los alemanes en Honduras: datos para su estudio, Honduras, Centro de Documentación de Honduras. 
Argueta, Mario, 1992a, Historia de los sin historia. 1900-1948, Tegucigalpa, Editorial Guaymuras.

Argueta, Mario, 1992b, Honduras y lo hondureño en la pluma de Rafael Heliodoro Valle, Tegucigalpa, Editorial Universitaria.

Argueta, Mario, 1993, Diccionario crítico de obras literarias hondureñas, Tegucigalpa, Editorial Guaymuras.

Argueta, Mario, 1998, Pasado y presente de la Secretaría de Gobernación y justicia, República de Honduras, Secretaría de Estado en los Despachos de Gobernación y Justicia.

Argueta, Mario, 2008, Tiburcio Carías: anatomía de una época, Tegucigalpa, Editorial Guaymuras.

Argueta, Mario, 2012, Tres caudillos, tres destinos, 1919-1932, Honduras, Ediciones Subirana.

Calò Carducci, Luigi, 2007, “El Perú: la tentación fascista y las relaciones con Italia en los años treinta", en Eugenia Scarzanella (compiladora), Fascistas en América del Sur, México, Fondo de Cultura Económica, pp. 93-165.

Cardona, Rafael, 1931, General Jorge Ubico. Presidente de la República para el período constitucional de 1931-1937, Guatemala, Ediciones de El Liberal Progresista.

Casaús, Marta y Teresa García, 2005, Las redes intelectuales centroamericanas: un siglo de imaginarios nacionales (1820-1920), Guatemala, F\&G Editores.

Ching, Erik, 2007, "El clientelismo y la política bajo Martínez 1931-1939", en Erik Ching, Carlos López y Virginia Tilley, Las masas, la matanza y el martinato en El Salvador. Ensayos sobre 1932, El Salvador: UCA Editores, pp. 139-185.

Ching, Erik, 2014, Authoritarian El Salvador: politics and the origins of the military regimes, 1880-1940, Notre Dame, Indiana, University of Notre Dame Press.

Dalton, Roque, 1972, Miguel Mármol: los sucesos de 1932 en El Salvador, Centroamérica, Editorial Universitaria Centroamericana (EDUCA)

Duby, Georges, 1991, La historia continúa, Madrid, Debate.

Gómez, Juan Pablo, 2015, Autoridad, cuerpo, nación: batallas culturales en Nicaragua (1930-1943), Managua, Instituto de Historia de Nicaragua y Centroamérica — de la Universidad Centroamericana.

González Izás, Matilde, 2014, Modernización capitalista, racismo y violencia. Guatemala (1750-1930), México, El Colegio de México.

Grieb, Kenneth, 1969, The United States and Huerta, Lincoln, University of Nebraska Press.

Grieb, Kenneth, 1971, "The United States and the Rise of general Maximiliano Hernández Martínez", Journal of Latin American Studies, 3(2), pp. 151-172.

Grieb, Kenneth, 1978a, "The Myth of a Central America Dictator' League", Journal of Latin American Studies 10 (2), pp. 329-345.

Grieb, Kenneth, 1978b, "Los Estados Unidos y el ascenso del general Maximiliano Hernández Martínez", en John Baily et al, El Salvador de 1840 a 1935: estudiado y analizado por los extranjeros, El Salvador, UCA Editores, pp. 243-269.

Grieb, Kenneth, 1979, Guatemala caudillo: The Regime of Jorge Ubico, Guatemala 19311944, Athens Ohio, Ohio University Press. 
Grieb, Kenneth, 1996, "El gobierno de Jorge Ubico", En Historia General de Guatemala, tomo V. Época contemporánea 1898-1944, Guatemala, Asociación Amigos del País, pp. 43-60.

Hall, Linda, 2014, "Álvaro Obregón y el movimiento agrario: 1912-1920", en David Brading (comp.), Caudillos y campesinos en la Revolución mexicana, México, Fondo de Cultura Económica.

Handy, Jim, 1996, "Enfrentándose al pulpo. Nacionalismo económico y cambio político en Guatemala y Costa Rica en la década de 1920", Mesoamérica, 31, pp. 11-39.

Lara Martínez, Rafael, 2011, Política de la cultura del martinato, El Salvador, Editorial Universidad Don Bosco.

Lara Martínez, Rafael, 2013, Del silencio y del olvido o los espectros del patriarca, El Salvador, AccesArte.

Lindo, Héctor, 2015, "La United Fruit Company y el empréstito de 1922 en El Salvador", Asociación para el Fomento de los Estudios Históricos en Centroamérica, 64, recuperado http://www.afehc-historia centroamericana.org/index_action_bul_aff_id_64. html

Lopes, Gilberto, 2013, Tras las huellas de Vicente Sáenz. A los 50 años de su muerte, Costa Rica, Editoriales Universitarias Públicas Costarricenses.

Luna, David, 1969, "Análisis de una dictadura fascista latinoamericana. Maximiliano Hernández Martínez 1931-1944", La Universidad. Revista bimestral de la Universidad de El Salvador, 94 (5), pp. 41-130.

Morán, Francisco, 1979, Las jornadas cívicas de abril y mayo de 1944, El Salvador, Editorial Universitaria.

Morlino, Leonardo, 2005, Democracias y democratizaciones, México, Centro de Estudios de Política Comparada.

Moro, Diana, 2014, "Escenas de lectura en Margarita, está linda la mar de Sergio Ramírez", Orbis Tertius, 19 (20), pp. 95-104.

Munro, Dana, 2013, Las cinco repúblicas de Centroamérica. Desarrollo político y económico y relaciones con Estados Unidos, Costa Rica; Editorial de la Universidad de Costa Rica.

Peña Kampy, Alberto, 1972, El general Martínez. Un patriarcal presidente dictador, El Salvador, Editorial Tipografía Ramírez.

Pérez Brignoli, Héctor, 2001, "Indios, comunistas y campesinos: la rebelión de 1932 en El Salvador", en William Roseberry, Mario Samper y Lowell Gudmuson (compiladores), Café, sociedad y relaciones de poder en América Latina, Costa Rica, EUNA, pp. 387-424.

Piel, Jean, 1995, El departamento del Quiché bajo la dictadura liberal (1880-1920), Guatemala, Facultad Latinoamericana de Ciencias Sociales.

Pitti, Joseph, 1975, Jorge Ubico and Guatemalan politics in the 1920's, tesis de doctorado inédita, Universidad de Nuevo México, Albuquerque.

Ramírez, Sergio, 1998, Margarita, está linda la mar, Madrid, Alfaguara.

Real Academia de la Lengua Española, 1992, Diccionario de la lengua española (tomo I). Madrid, Talleres Gráficos Peñalara.

Ríos, Efraín de los, 1948, Ombres contra hombres, Guatemala, Tipografía Nacional. 
Sabino, Carlos, 2013, Tiempos de Jorge en Guatemala y el mundo, Guatemala, Fondo de Cultura Económica.

Sáenz, Vicente, 1944, Centroamérica en pie, Ciudad de México, Ediciones Liberación.

Taracena, Arturo, 1989, "El primer partido comunista de Guatemala (1922-1923). Diez años de una historia olivada", Anuario de Estudios Centroamericano, Universidad de Costa Rica, 15 (1), pp. 49-63.

Taracena, Arturo, 1993, "Liberalismo y poder político en Centroamérica (1870-1929)", en Edelberto Torres Rivas (coord.), Historia general de Centroamérica. España. Facultad Latinoamericana de Ciencias Sociales, pp. 167-253.

Taracena, Arturo, 2017, Guatemala, la República Española y el Gobierno Vasco en el exilio (1944-1954). México, Universidad Nacional Autónoma de México y El Colegio de Michoacán.

Turcios, Roberto, 2000, "Los años del general 1931-1948" en La República. tomo II El Salvador, Fondo Cultural Banco Agrícola. pp. 406-439.

Urbina, Nicasio, 2004, "Violencia y estructura en Margarita está linda la mar, de Sergio Ramírez", Revista Iberoamericana, 207, pp. 359-370

Vilar, Pierre, 1992, La guerra civil española, Barcelona, Crítica.

Walter, Knut, 2004, El régimen de Anastasio Somoza: 1936-1956, Managua, Universidad Centroamericana - Instituto de Historia de Nicaragua y Centroamérica.

Wilson, Everett, 2004, La crisis de la integración nacional en El Salvador, 1919-1935, El Salvador, Dirección de Publicaciones e Impresos.

Wünderich, Volker, 2009, Sandino: una biografía política, Nicaragua, Universidad Centroamericana-Instituto de Historia de Nicaragua y Centroamérica.

\section{Cómo citar este artículo:}

Monterrosa Cubías, Luis Gerardo, 2019, «Los regímenes autoritarios centroamericanos de los años treinta. Balance historiográfico y perspectivas de investigación», Revista Pueblos y fronteras digital, volumen 14, e-396. https://doi.org/10.22201/cimsur.18704115e.2019.v14.396 